\title{
Alarm Tones, Voice Warnings, and Musical Treatments: A Systematic Review of Auditory Countermeasures for Sleep Inertia in Abrupt and Casual Awakenings
}

\author{
Stuart J. McFarlane ${ }^{1, *} \mathbb{D}$, Jair E. Garcia ${ }^{1}\left(\mathbb{D}\right.$, Darrin S. Verhagen ${ }^{2}$ and Adrian G. Dyer ${ }^{1} \mathbb{C}$ \\ 1 Bio-Inspired Digital Sensing Lab (BIDS), School of Media and Communication, Digital Ethnography \\ Research Centre (DERC), RMIT University, Melbourne, VIC 3001, Australia; jair.garcia@rmit.edu.au (J.E.G.); \\ adrian.dyer@rmit.edu.au (A.G.D.) \\ 2 School of Design, RMIT University, Melbourne, VIC 3001, Australia; darrin.verhagen@rmit.edu.au \\ * Correspondence: stuart.mcfarlane2@rmit.edu.au
}

Received: 25 August 2020; Accepted: 16 October 2020; Published: 20 October 2020

\begin{abstract}
Sleep inertia is a measurable decline in cognition some people experience upon and following awakening. However, a systematic review of the current up to date evidence of audio as a countermeasure has yet to be reported. Thus, to amend this gap in knowledge, the authors conducted this systematic review beginning with searches in three primary databases for studies published between the inception date of each journal and the year 2020. Search terms contained "Sleep Inertia" paired with: "Sound"; “Noise"; "Music"; "Alarm"; "Alarm Tone"; "Alarm Sound"; "Alarm Noise"; "Alarm Music"; "Alarm Clock"; "Fire Alarm", and "Smoke Alarm". From 341 study results, twelve were identified for inclusion against a priori conditions. A structured narrative synthesis approach generated three key auditory stimulus themes-(i) Noise, (ii) Emergency tone sequences; Voice Alarms and Hybrids, and (iii) Music. Across themes, participants have been assessed in two situational categories: emergency, and non-emergency awakenings. The results indicate that for children awakening in emergency conditions, a low pitch alarm or voice warnings appear to be more effective in counteracting the effects of sleep inertia than alarms with higher frequencies. For adults abruptly awakened, there is insufficient evidence to support firm conclusions regarding alarm types and voice signals. Positive results have been found in non-emergency awakenings for musical treatments in adults who preferred popular music, and alarms with melodic qualities. The results observed reflect the potential for sound, voice, and musical treatments to counteract sleep inertia post-awakening, and emphasize the requirements for further research in this domain.
\end{abstract}

Keywords: sleep inertia; sleep; auditory countermeasures; human performance; emergency awakenings; non-emergency awakenings; alarm tones; voice signals; music

\section{Introduction}

"I've woken up actually holding my pager and actually pressed the button on the pager and went straight back to sleep again". A firefighter describing an incident when responding to their on-call auditory alarm during an emergency [1].

Sleep Inertia $(S I)$ is an experienced and quantifiable reduction in human performance that occurs upon and post-awakening [2-4]. The performance decrements observed during SI have been shown to expire typically within $30 \mathrm{~min}$; however, durations of up to $4 \mathrm{~h}$ have been reported [2,5-9]. Research suggests that the duration and severity may be linked to several factors, including sleep stage at awakening [6,10-14], sleep deprivation [15-20], and time of day [14,21,22]; however, these factors do 
not guarantee that $S I$ will be abolished in all circumstances. The cognitive impairments examined to be associated with SI include, yet are not limited to, reaction time (RT) [23-25], accuracy [19], memory [26] and complex decision making [11,27]. In a real-world context, the reductions in human functioning as a result of SI pose an increased risk for general activities occurring post-awakening (e.g., driving, bike riding), and personnel operating in high-risk conditions, including first responders (e.g., police, and the fire brigade), and logistics (air, road, and sea) [1,28,29]. Thus, SI is frequently highlighted as a phenomenon requiring improved understanding and further research spanning many fields to mitigate such occurrences [30-36].

Preemptive measures seek to reduce the envisioned impacts of SI through managed sleep epochs and napping [37-40]. However, these approaches do not compensate for unforeseen events, emergencies, or lifestyle commitments that may inhibit the ability to structure sleep-wake cycles or promote thorough sleep hygiene. For example, during on-call working arrangements where events cannot be predicted, a respondent must take action regardless of the sleep stage prior to awakening, time of day, or prior sleep duration [1]. Furthermore, in regular day to day awakenings, sleep deprivation which is a known factor that enhances SI [41,42] is increasingly becoming a prevalent occurrence within populations $[43,44]$. Thus, post-awakening countermeasures are conceptualized and researched to address these concerns by considering habitual behaviors, environmental conditions, and awakening routines. These include caffeine intake [23,45-48], lighting treatments [25,47,49-51], temperature [52,53], post-awakening routines [47,54], and applied stress [55]. Concerning the potential for sound to counteract $S I$, existing reviews of $S I$ literature contain four instances where auditory countermeasures have been acknowledged [2-4,56]; however, within these four reviews, only two original research studies are identified for discussion that interrogate noise and music [57,58].

The rationale for auditory signals to have the potential to counteract SI stems from research in the fields of auditory perception and cognition. It has been shown that in alert humans noise (e.g., White noise: A random auditory signal having equal intensity at different frequencies) [59-61], environmental sounds (e.g., Boiling water) [62], and music (e.g., Rock; Classical) can potentially enhance arousal and improve task performance [63-67]. In the awakening of sleeping humans, auditory arousal thresholds (AATs) have been researched to understand the time it may take an individual to awaken in response to different alarm tone designs and signal loudness (measured in Decibel [dB]) (See Thomas and Bruck [68] for a review). However, the cognitive benefits attributed to the soundings post-awakening are infrequently measured or reported. By undertaking this systematic review, we aim to update and expand the existing empirical-based evidence that reports post-awakening auditory effects on $\mathrm{SI}$, and by doing so, inform researchers and industry of auditory approaches that may be further examined or implemented.

\section{Methods}

In the production of this review, the authors (SJM, AGD) applied the PRISMA statement guidelines where applicable [69] (Table S1). Secondly, an a priori search strategy was developed in accordance to the PRISMA-P [70] guidelines (Item No. 10).

\subsection{Eligibility Criteria}

Eligible articles were required to report original research on the analysis of SI in subjects post-awakening to auditory stimuli (objectively or subjectively). All laboratory, field and mixed-method studies employing either electroencephalographic (EEG) or non-EEG confirmed awakenings were included. No limitations were imposed on the types of auditory stimuli tested, nor participant age, sex, or gender. All eligible articles were required to be published in English, report healthy (unimpaired) human experimental results, and be published in peer-reviewed or refereed journals. All publications dates were accepted. Qualitative analysis studies and reviews (not original research) were excluded. 


\subsection{Information Sources, Search Strategy and Study Selection}

The primary search strategy employed three electronic databases (ProQuest, PubMed, and Scopus) on the 15 March 2020 to search for the following term "Sleep Inertia" coupled with: "Sound"; "Noise"; "Music"; "Alarm"; "Alarm Tone"; "Alarm Sound"; "Alarm Noise"; "Alarm Music"; "Alarm Clock"; "Fire Alarm", and "Smoke Alarm". This resulted in $n=341$ articles. One hundred and forty $(n=140)$ duplicate articles were identified and removed from the total leaving two hundred and one $(n=201)$ for screening. A further $(n=187)$ records were excluded that did not meet the inclusion criteria based on Title, Abstract and Methodological screening. The remaining fourteen $(n=14)$ articles were reviewed through full-text assessment resulting in nine $(n=9)$ omissions based on the inclusion/exclusion criteria. One article was excluded due to unrelated study procedures that may have confounded results which the authors acknowledge and attribute to the insignificant findings [55]. Each remaining article $(n=5)$ reference list was then manually assessed for additional records which resulted in the identification of $n=1$ study to be included. Additionally, all lead authors' (Dorothy Bruck; Mitsuo Hayashi; Stuart J. McFarlane; Gary A. Smith; Patricia Tassi) publication records from the six articles identified for inclusion were individually searched in Google Scholar to verify that no associated literature may have been overlooked through publication and search term bias [71]. Google scholar was chosen as the preferred electronic search engine as it has been shown to be the most comprehensive, yet sometimes imprecise tool currently available [72]. The search was conducted on the 21 May 2020. After excluding duplicates from the search process outlined above, six $(n=6)$ additional articles were identified that adhered to the inclusion/exclusion criteria, extending the total number of articles for review to twelve $(n=12)$. See Figure 1 for the screening flow diagram. 


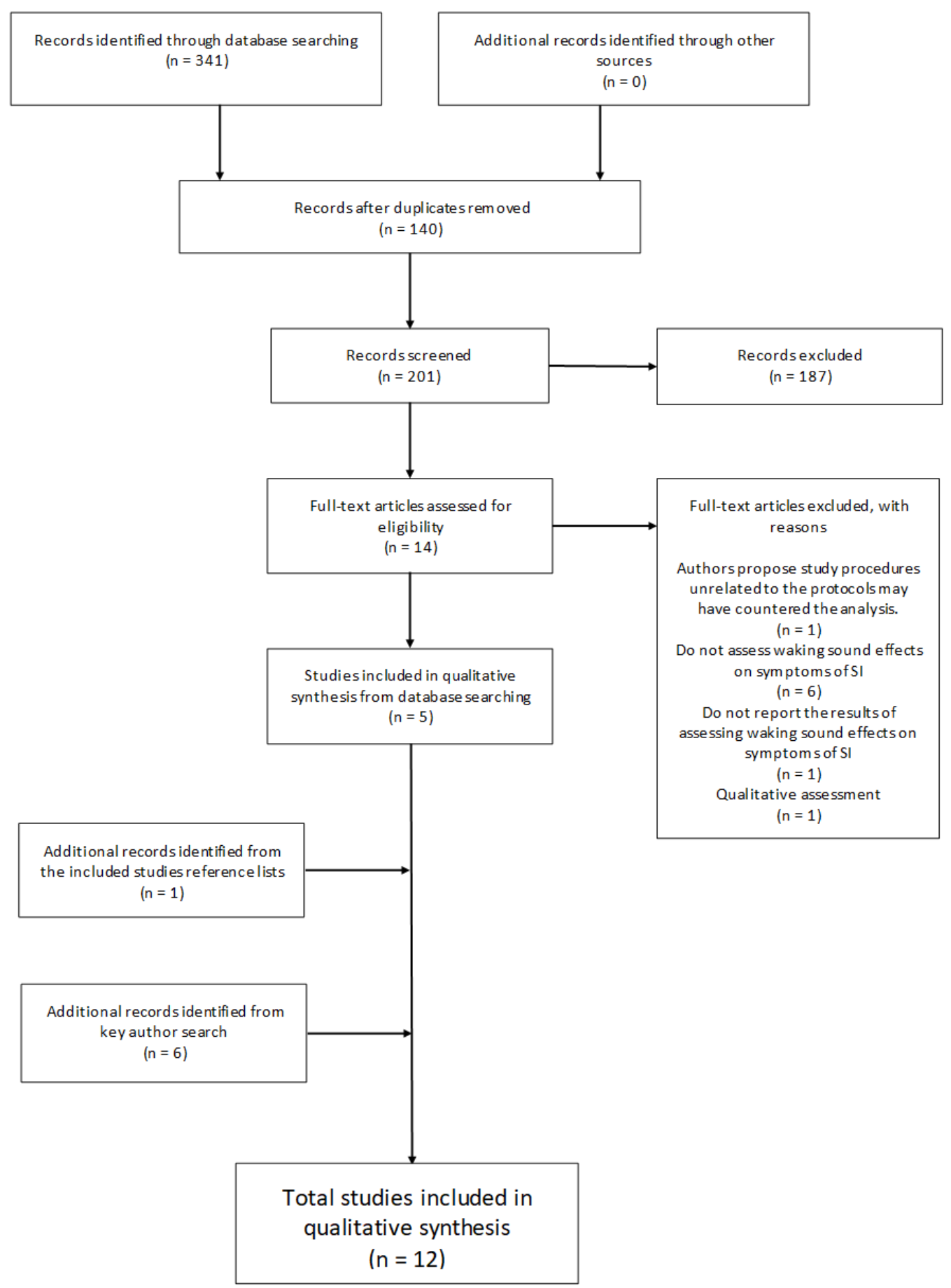

Figure 1. Flowchart illustrating the review selection process.

\subsection{Data Collection Process and Data Items}

To extract data from each selected article, the researchers used forms to tabulate specific attributes of all studies which highlight the relevant information necessary to assist in the aims of the review [73]. This information was categorized into the following sections: Author, Number of participants $(n)$, Age, Sex or Gender, Setting, Study design, Sleep duration, Awakening time, Stimulus, Decibel (dB), EEG-confirmed awakening (Yes/No), Objective measure, and Subjective measure; where the inserted (Yes/No) indicates a binary categorization whilst other factors were expressed as reported variables. See Table 1 for a summary of the articles selected. 
Table 1. Chronological summary of studies analyzing auditory alarms and symptoms of SI post-awakening

\begin{tabular}{|c|c|c|c|c|c|c|c|c|c|c|c|c|}
\hline Author & Setting & $n$ & Age & $\begin{array}{l}\text { Sex or } \\
\text { Gender }\end{array}$ & Study Design & Sleep Duration & $\begin{array}{l}\text { Awakening } \\
\text { Time }\end{array}$ & $\begin{array}{c}\text { EEG } \\
\text { Confirmed } \\
\text { Awakening } \\
\end{array}$ & Stimulus & dB & Objective Measure & Subjective Measure \\
\hline $\begin{array}{c}\text { Tassi, } \\
\text { Nicolas et al. } \\
\text { (1992) }\end{array}$ & Lab & 44 & $19-27$ & Male & $\begin{array}{l}\text { Controlled, } \\
\text { nonblinded, } \\
\text { repeated } \\
\text { measures }\end{array}$ & $1 \mathrm{~h}$ & $\begin{array}{l}\text { 01:00 } \\
\text { 04:00 }\end{array}$ & Yes & $\begin{array}{l}\text { Control/Baseline: } \\
\text { No-noise } \\
\text { Experimental: } \\
\text { Pink noise }\end{array}$ & 75 & $\begin{array}{l}\text { All test groups: } \\
\text { Spatial Memory Test }\end{array}$ & None \\
\hline $\begin{array}{c}\text { Bruck and } \\
\text { Horasan (1995) }\end{array}$ & Lab & 24 & $18-24$ & $\begin{array}{c}\text { Male } \\
\text { Female }\end{array}$ & $\begin{array}{l}\text { Non-blinded, } \\
\text { observational } \\
\text { study }\end{array}$ & NR & NR & Yes & $\begin{array}{l}\text { Control/Baseline: } \\
\text { None } \\
\text { Experimental: } \\
\text { High frequency 'pulse' } \\
\text { sequence alarm } \\
\end{array}$ & $55-65$ & $\begin{array}{l}\text { All participants: } \\
\text { Reaction time (RT) }\end{array}$ & $\begin{array}{l}\text { All participants: } \\
\text { Sleep quality } \\
\text { Sleep quantity }\end{array}$ \\
\hline Bruck (1999) & Field & 36 & 6-59 & $\begin{array}{c}\text { Male } \\
\text { Female }\end{array}$ & $\begin{array}{l}\text { Non-blinded, } \\
\text { repeated } \\
\text { measures }\end{array}$ & NR & 01:00-04:30 & No & $\begin{array}{c}\text { Control/Baseline: } \\
\text { None } \\
\text { Experimental: } \\
\text { Smoke alarm }\end{array}$ & 60 & $\begin{array}{l}\text { All test groups: } \\
\text { Wrist actigraphy }\end{array}$ & $\begin{array}{c}\text { All test groups: } \\
\text { Clear-headedness scale } \\
\text { KSS }\end{array}$ \\
\hline $\begin{array}{l}\text { Hayashi, } \\
\text { Uchida et al. } \\
\text { (2004) }\end{array}$ & Lab & 16 & $20-23$ & $\begin{array}{l}\text { Male } \\
\text { Female }\end{array}$ & $\begin{array}{l}\text { Controlled, } \\
\text { non-blinded }\end{array}$ & $20 \mathrm{~min}$ & 14:20 & Yes & $\begin{array}{c}\text { Control/Baseline: } \\
\text { Intercom } \\
\text { Experimental: } \\
\text { (1) Participant choice } \\
\text { (2) Selected by the experimenter }\end{array}$ & 60 & $\begin{array}{l}\text { Control group: } \\
\text { Memory search task } \\
\text { Experimental group: } \\
\text { Visual oddball task }\end{array}$ & $\begin{array}{l}\text { All test groups: } \\
\text { Sleepiness rating } \\
\text { Comfort rating }\end{array}$ \\
\hline $\begin{array}{l}\text { Bruck, Reid et al. } \\
\text { (2004) }\end{array}$ & Field & $\begin{array}{l}\text { (S1) } 20 \\
\text { (S2) } 14 \\
\text { (S3) } 14\end{array}$ & $6-10$ & $\begin{array}{c}\text { Male } \\
\text { Female }\end{array}$ & $\begin{array}{l}\text { Non-blinded, } \\
\text { repeated } \\
\text { measures }\end{array}$ & NR & $\begin{array}{l}\text { 01:00 } \\
\text { 03:00 }\end{array}$ & No & $\begin{array}{c}\text { Control/Baseline: } \\
\text { None } \\
\text { Experimental: } \\
\text { (1) Mothers voice } \\
\text { (2) Female actors voice } \\
\text { (3) High frequency 'pulse' } \\
\text { sequence alarm } \\
\text { (4) Low-frequency T-3 } \\
\text { tone alarm }\end{array}$ & 89 & $\begin{array}{l}\text { All test groups: } \\
\text { Wrist actigraphy }\end{array}$ & $\begin{array}{l}\text { All test groups: } \\
\text { Clear-headedness scale } \\
\text { Adapted KSS }\end{array}$ \\
\hline $\begin{array}{l}\text { Smith, } \\
\text { Splaingard et al. } \\
\text { (2006) }\end{array}$ & Clinical & 24 & 6-12 & $\begin{array}{c}\text { Male } \\
\text { Female }\end{array}$ & $\begin{array}{l}\text { Randomized, } \\
\text { non-blinded }\end{array}$ & NR & $\begin{array}{c}\text { Awakened } \\
\text { during the } \\
\text { first two } S 4 S \\
\text { cycles }\end{array}$ & Yes & $\begin{array}{c}\text { Control/Baseline: } \\
\text { None } \\
\text { Experimental: } \\
\text { (1) Mothers voice } \\
\text { (2) High-frequency T-3 } \\
\text { tone alarm } \\
\end{array}$ & 100 & $\begin{array}{l}\text { All test groups: } \\
\text { Self-rescue sequence }\end{array}$ & None \\
\hline $\begin{array}{l}\text { Splaingard, } \\
\text { Hayes et al. } \\
\text { (2007) }\end{array}$ & Clinical & 44 & $6-12$ & $\begin{array}{c}\text { Male } \\
\text { Female }\end{array}$ & $\begin{array}{l}\text { Non-blinded, } \\
\text { observational } \\
\text { study }\end{array}$ & $\begin{array}{l}\text { Cycle 1: } \sim 65 \mathrm{~min} \\
\text { Cycle 2: } \sim 50 \mathrm{~min} \\
\text { Mean time between } \\
\text { alarms } 76 \mathrm{~min}\end{array}$ & $\begin{array}{c}\text { Awakened } \\
\text { during the } \\
\text { first two } S 4 S \\
\text { cycles }\end{array}$ & Yes & $\begin{array}{c}\text { Control/Baseline: } \\
\text { None } \\
\text { Experimental: } \\
\text { (1) T-3 tone alarm } \\
\text { (2) Mother's voice } \\
\text { (3) Hybrid alarm (T-3 tone alarm } \\
\text { and vibration wand) }\end{array}$ & 100 & $\begin{array}{l}\text { All test groups: } \\
\text { PVT (10-min) } \\
\text { Self-rescue sequence }\end{array}$ & None \\
\hline
\end{tabular}


Table 1. Cont

\begin{tabular}{|c|c|c|c|c|c|c|c|c|c|c|c|c|}
\hline Author & Setting & $n$ & Age & $\begin{array}{l}\text { Sex or } \\
\text { Gender }\end{array}$ & Study Design & Sleep Duration & $\begin{array}{l}\text { Awakening } \\
\text { Time }\end{array}$ & $\begin{array}{c}\text { EEG } \\
\text { Confirmed } \\
\text { Awakening }\end{array}$ & Stimulus & $\mathrm{dB}$ & Objective Measure & Subjective Measure \\
\hline $\begin{array}{l}\text { Smith, } \\
\text { Chounthirath et al. } \\
\text { (2019) }\end{array}$ & Clinical & 176 & $5-12$ & $\begin{array}{l}\text { Male } \\
\text { Female }\end{array}$ & $\begin{array}{l}\text { Randomized, } \\
\text { non-blinded, } \\
\text { repeated } \\
\text { measures }\end{array}$ & NR & $\begin{array}{c}\text { Awakened } \\
\text { during the } \\
\text { first two S4S } \\
\text { cycles }\end{array}$ & Yes & $\begin{array}{c}\text { Control/Baseline: } \\
\text { High-frequency T-3 tone alarm } \\
\text { Experimental: } \\
\text { (1) Maternal voice (Name only) } \\
\text { (2) Maternal voice } \\
\text { (Instructions only) } \\
\text { (3) Maternal voice (Name and } \\
\text { instructions) }\end{array}$ & 85 & $\begin{array}{l}\text { All test groups: } \\
\text { Self-rescue sequence }\end{array}$ & None \\
\hline $\begin{array}{l}\text { McFarlane, } \\
\text { Garcia et al. } \\
\quad(2020)\end{array}$ & Field & 50 & $18+$ & $\begin{array}{l}\text { Male } \\
\text { Female }\end{array}$ & $\begin{array}{l}\text { Blind, } \\
\text { questionnaire }\end{array}$ & NR & $\begin{array}{l}\text { Following } \\
\text { nocturnal } \\
\text { sleep }\end{array}$ & No & Participant specified & $\begin{array}{l}\text { Self-report } \\
\text { subjective } \\
\text { scale }\end{array}$ & None & $\begin{array}{c}\text { All participants: } \\
\text { Self-report } \\
\text { questionnaire } \\
\text { including: } \\
\text { Sleep Inertia } \\
\text { Questionnaire (SIQ) } \\
\text { Music element ratings } \\
\text { Sound type } \\
\text { Feeling toward the } \\
\text { sound rating }\end{array}$ \\
\hline $\begin{array}{l}\text { Smith, } \\
\text { Chounthirath et al. } \\
\text { (2020) }\end{array}$ & Clinical & 188 & $5-12$ & $\begin{array}{l}\text { Male } \\
\text { Female }\end{array}$ & $\begin{array}{l}\text { Randomized, } \\
\text { non-blinded, } \\
\text { repeated } \\
\text { measures }\end{array}$ & NR & $\begin{array}{l}\text { Awakened } \\
\text { during the } \\
\text { first two S4S } \\
\text { cycles }\end{array}$ & Yes & $\begin{array}{c}\text { Control/Baseline: } \\
\text { None } \\
\text { Experimental: } \\
\text { (1) Female voice } \\
\text { (2) Male voice } \\
\text { (3) Hybrid voice-tone alarm } \\
\text { (Low-frequency T-3 tone alarm } \\
\text { and female voice) } \\
\text { (4) High-frequency T-3 } \\
\text { tone alarm }\end{array}$ & 85 & $\begin{array}{l}\text { All test groups: } \\
\text { Simulated escape } \\
\text { procedure }\end{array}$ & None \\
\hline $\begin{array}{l}\text { Smith, } \\
\text { Chounthirath et al. } \\
\text { (2020) }\end{array}$ & Clinical & 176 & $5-12$ & $\begin{array}{c}\text { Male } \\
\text { Female }\end{array}$ & $\begin{array}{l}\text { Randomized, } \\
\text { non-blinded, } \\
\text { repeated } \\
\text { measures }\end{array}$ & NR & $\begin{array}{c}\text { Awakened } \\
\text { during the } \\
\text { first two S4S } \\
\text { cycles }\end{array}$ & Yes & $\begin{array}{l}\text { Control/Baseline: } \\
\text { None } \\
\text { Experimental: } \\
\text { (1) Child's mother voice } \\
\text { (2) Female strangers voice } \\
\text { (3) Low-frequency T-3 } \\
\text { tone alarm } \\
\text { (4) High-frequency T-3 } \\
\text { tone alarm }\end{array}$ & 85 & $\begin{array}{l}\text { All test groups: } \\
\text { Simulated escape } \\
\text { sequence }\end{array}$ & None \\
\hline $\begin{array}{l}\text { McFarlane, } \\
\text { Garcia et al. } \\
\text { (2020) }\end{array}$ & Field & 20 & $18-49$ & $\begin{array}{c}\text { Male } \\
\text { Female }\end{array}$ & $\begin{array}{l}\text { Controlled, } \\
\text { non-blinded, } \\
\text { repeated } \\
\text { measures }\end{array}$ & $\begin{array}{l}\text { Group A \& B: } \\
\text { 5-9+ }\end{array}$ & $\begin{array}{l}\text { Following } \\
\text { nocturnal } \\
\text { sleep }\end{array}$ & No & $\begin{array}{l}\text { Control: } \\
\text { Tonal pulse } \\
\text { Experimental: } \\
\text { (1) Melodic } \\
\text { (2) Rhythmic }\end{array}$ & None & $\begin{array}{l}\text { All test groups: } \\
\text { PVT (3 min) }\end{array}$ & $\begin{array}{c}\text { All test groups: } \\
\text { KSS } \\
\text { Hours Slept } \\
\text { Sleep Quality Scale }\end{array}$ \\
\hline
\end{tabular}

Table Abbreviations: NR (Not reported); KSS (Karolinska Sleepiness Scale); PVT (Psychomotor Vigilance Test); S4S (Sleep Stage 4); T-3 (Temporal three smoke alarm); dB (Decibel); S1, S2, S3 (Study No). 


\subsection{Analysis of Bias}

Due to the observed inconsistencies (i.e., methodology, data points, measures, stimulus) between studies in the final article group following full-text screening, and acknowledging the current lack of research in this particular field [3,56], assessment of bias [74] using tools such as the 'Standard Quality Assessment Criteria for Evaluating Primary Research Papers from a Variety of Fields' [75] was not considered beneficial by the authors (SJM, AGD) for this review, as identified limitations within studies may render seminal results or insights ineligible. As a substitute to this assessment, we qualitatively addressed study limitations and bias in the discussion section of this manuscript to help provide a framework for future research to improve the current knowledge base. Furthermore, the structuring of our methods will likely serve to help reduce bias in future research.

\subsection{Data Synthesis}

A structured narrative synthesis approach [76] was agreed upon between the researchers (SJM, AGD) for this review as it is sympathetic to the synthesis of findings and results from studies with diverse features (e.g., study design, methodologies, samples, and measures). Familiarization of each included article through full-text screening and the data extraction process enabled the generation of key research themes to assist the reviews analytical narrative thus ensuring the full scope of the data is captured.

\section{Results}

The total studies included in this qualitative assessment following full-text screening adhere to the inclusion and exclusion criteria (See Eligibility Criteria). The majority of ineligible articles did not directly analyze sound and its effects on symptoms of SI post-awakening, were qualitatively analyzed, or were unoriginal research (Figure 1). The geographical location of the research included was primarily conducted in English speaking, Western nations. Five were conducted in the United States of America [77-81]; five in Australia [82-86]; one in France [58] with one in Japan [57]. The publication dates of all articles range from 1992 to 2020 with five published between 2019 and 2020, indicating the increased interest in the topic. Eight studies $[57,58,77-81,86]$ were conducted in laboratory settings (Controlled, nonblinded, repeated measures [ $n=1]$; Controlled, non-blinded [ $n=1]$; Randomized, nonblinded, repeated measure designs [ $n=3]$; Randomized, non-blinded $[n=1]$, and non-blinded observational studies [ $n=2]$ ), and four in the field (Controlled, non-blinded, repeat measures $[n=1]$; Non-blinded, repeated measures [ $n=2]$, Blind questionnaire $[n=1])$. Participant sample size ranged from $n=16$ to $n=188$ in the laboratory studies, and $n=14$ to $n=50$ for the field studies. Six studies [77-82] tested children participants ranging in age between 5 and 16 years old, one study tested children and adults (6-59) [86], and five studies analyzed adult participants aged from 18 years and above. One study tested males only [58], whilst the remaining eleven studies tested included participants of all gender specifications. Eight articles do not specifically report participant sleep duration [77-79,81-83,85,86] and eight did not report awakening time [77-81,83-85]. Observed differences and combinations of awakening measurement techniques included: EEG-confirmed sleep-stage at awakening $(n=8)$; Non EEG-confirmed awakenings ( $n=4$; Predetermined awakening time [ $n=2]$; Natural awakenings $[n=2])$. Test stimuli vary in type and context between studies. Eight studies examined sound in an emergency awakening scenario with audio treatments that include domestic fire alarms, human voice, or hybrid combinations $[77-82,85,86]$. Three studies examine music $[57,83,84]$, and one tested noise [58]. Alternate stimulus includes an intercom $(n=1)$ [57] multi-modal conditions which combine sound and vibration $(n=1)$ [80], and voice and alarm $(n=1)$ [79]. Ten of the studies reported on stimulus loudness using the decibel scale (dB; perceived as loudness), where readings for the stimulus treatments ranged between $\sim 60 \mathrm{~dB}$ and $100 \mathrm{~dB}(60 \mathrm{~dB}[n=3] ; 75 \mathrm{~dB}[n=1] ; 85 \mathrm{~dB}[n=3] ; 89 \mathrm{~dB}$ $[n=1] ; 100 \mathrm{~dB}[n=2])$. A subjective 5-point self-report of loudness presented in one article ranged from 'Low volume' to 'Very high in volume' with $44 \%$ reporting 'Neither high-nor low in volume' [83]. 
The objective and subjective measures employed in the articles differ markedly. All but one study employed objective measures [83], while six did not record subjective measurements [58,77-81].

To assist this review, three primary themes were identified for synthesis which encapsulate the entirety of the auditory stimulus tested within and between studies. These are: Noise [58], Emergency tone sequences; Voice Alarms and Hybrids [77-82,85,86], and Music [57,83,84].

\subsection{Noise}

Through the testing of two conditions (Baseline [no nap, no noise; no nap, noise]; Experimental [nap-no noise, nap-noise]) over two separate nights in a counterbalanced design, Tassi et al. [58] aimed to evaluate the effects of a $5000 \mathrm{~Hz}$ pink noise signal (similar to white noise with predominantly lower frequencies) delivered at $75 \mathrm{~dB}$ on participant spatial memory performance following awakening from 1-h naps placed at 00:00 $\mathrm{h}$ and 03:00 $\mathrm{h}$. With noise presented, no difference was observed between reaction time (RT) performance in the Baseline (no-nap) and Experimental (nap) conditions at 01:00 h. Without the presentation of noise, performance was inferior for up to $15 \mathrm{~min}$ in the Experimental (nap) condition compared to the Baseline (no-nap). The observed difference between conditions suggests that pink noise may have improved performance by reducing the expected effects of SI following awakening. However, these results did not translate during the later test session, as pink noise was shown to be ineffective and potentially exacerbate performance decrement. These conflicting findings between test epochs and pink noise effects are hypothesized to be a potential result of sleep stages upon awakening; however, at the preliminary stage of this research, the study authors [58] acknowledge no firm conclusion, thus further research is required.

\subsection{Emergency Alarms; Tone Sequences, Voice and Hybrids}

Several studies $[77-82,85,86]$ have analyzed fire alarms and their influence on human performance following abrupt awakenings in pseudo-emergency scenarios. Within these investigations a variety of experiment designs and stimulus comparisons have been made, and a clear focus on the age demographics of participants has been pursued, specifically children/minors (6-17 years) and adults (18+ years).

\subsubsection{Children}

The first study to analyze the effect a smoke detector alarm exhibits on child/juniors (6-17 years [Mean 11.6 years]) awakenings and subjective SI was conducted by Bruck [86] in 1999. In this research, the author simultaneously tested the parents/guardians to enable an age group comparison between results. Conducted in residential conditions over a four-night program with tests occurring on the second and third nights without the participants' knowledge, the thirty-six subjects ( 22 children) were exposed to an alarm at $60 \mathrm{~dB}$ between 01:00 and 04:30 h. Through the collection of each subject's objective and subjective data (wrist actigraphy, self-report questionnaires) upon and post-awakening, the results reveal that $85 \%$ of the children's group slept through one or both of the alarm presentations, while $100 \%$ of the adults consistently awoke to both. For successful awakenings, $95 \%$ of all subjects did so within $32 \mathrm{~s}$ of the alarm sounding. Concerning ratings of subjective SI (clear-headedness), no significant difference was observed between groups. Across the test groups, an average rating of 'moderately clear-headed' was reported immediately following awakening; however, no significant difference was reported between subsequent test points (1. At first alarm hearing; 2. $\sim 3$ min after awakening; 3. 4-7 min after awakening). The mean Karolinska Sleepiness Scale (KSS) values for both test nights corresponded to an equivalent ranking of neither sleepy nor alert. This seminal study reveals that a smoke alarm deployed at $60 \mathrm{~dB}$ is inferior in awakening younger participants than older; however, for successful awakenings across groups, the subjective measures of $S I$ were reported to be not significantly different [86].

In subsequent research, Bruck and Reid [82] compared results between three independent field studies she and her colleagues had previously undertaken which tested a mother's and female actor's 
voice relaying an escape notification (Mother: "There is a fire! Wake up now! Quickly go outside! Actor: "Danger! There is a Fire! Wake up now and go and investigate!" [315 Hz-2500 Hz]) (Study 1); a low pitch Temporal three (T-3) signal $(500 \mathrm{~Hz}$ ) (Study 2), and a high pitch Australian standard 'pulse' signal $(\sim 4000 \mathrm{~Hz})$ on child participants deployed at $\sim 89 \mathrm{~dB}$ (Study 3). In Study 1 participants were alerted at 01:00 h, while Studies 2 and 3 alerted subjects at 01:00 $\mathrm{h}$ and 03:00 h. Ratings of clear-headedness were recorded at three different time points (i.e., when the alarm first went off; when the subjects exited their bed; when completing the questionnaire outside the bedroom) and an adapted KSS was completed $\sim 7$ min following awakening. Across studies, successful awakenings were statistically significantly inferior for the Australian standard signal compared to the voice and low pitch T-3 signals. Similarly, participant sleep latency was significantly greater on arousal when awakening to the standard alarm. The analysis of subjective SI (clear-headedness) revealed no significant difference between alarm type (with a majority of rankings between 2 [quite a bit clear-headed] and 3 [moderately clear-headed]), or improvement over time. Further, the mean KSS sleepiness ratings of all alarms correspond to an approximate rating of 2 (sleepy but no difficulty staying awake) and less than 3 (neither sleepy nor alert); however, no statistically significant difference was observed between treatments. Concerning the effectiveness of emergency alarm tone sequences on objective performance in children, this analysis demonstrates that a high-pitched signal 'pulse' appears to be less effective in arousal than a mixed temporal sequence with lower frequencies. Additionally, all reported stimuli in this study show evidence of a positive effect on reducing subjective SI (clear-headedness) with a moderate influence on perceived sleepiness.

Researchers Smith, Splaingard, and colleagues have together produced a collection of studies which build on and refine Bruck et al.'s [82] original research focus. The first study [77] compared the effectiveness of a $100 \mathrm{~dB}$ parent voice alarm ("First name! First name! Wake up! Get out of bed! Leave the room!") with a high pitch T-3 tone alarm $(\sim 4000 \mathrm{~Hz})$ in prompting participants to awaken and perform a self-rescue procedure. Conducted in a laboratory setting following a randomized, unblinded design, each subject was awakened during the first two-stage 4 sleep cycles (S4S). The results in this study reveal that the voice treatment significantly outperformed the high pitch T-3 alarm in awakening participants. Additionally, the subjects were significantly more likely to complete the escape procedure within 5-min and 3-min time bins from awakening to the parent voice alarm than the high pitch temporal signal.

Conducted under a similar protocol to Smith et al. [77], the previous year, Splaingard et al. [80] analyzed RT performance following awakening from $S 4 S$ to a loud $(100 \mathrm{~dB})$ parent voice alarm message and T-3 signal, with the addition of a hybrid alarm version (T-3 and vibration wand placed under the pillow). In all conditions participant RTs were significantly slower than baseline readings; however, the hybrid alarm produced significantly faster RTs than parent voice and tone-only alarm. There was no significant difference reported for performance between the parent voice and tone alarm. Furthermore, the RTs of all treatments following the first S4S awakening were significantly shorter that the second awakening. With respect to awakenings and escape procedure performance, no significant different was reported between subjects who successfully awakened and escaped to those who did not.

More recent studies by Smith et al. [78,79,81] continue this line of inquiry by the repeated testing of participant performance when awakened from S4S and completing a self-rescue sequence. The first [78] assessed the effectiveness of three maternal voice alarms: Name only ("Name, Name! Name, Name! Name, Name!"); Instructions only ("Name, Name! Wake up! Get out of bed! Leave the room!"), and Name and Instructions comparative to a high pitched $(\sim 3200 \mathrm{~Hz})$ T-3 residential fire alarm. The second [79] compared a female and male voice reciting the escape instructions delivered in the previous study ("Fire! Fire! Wake up! Get out of bed! Leave the room!"), a hybrid alarm consisting of a low-frequency T-3 $(500 \mathrm{~Hz})$ signal plus a female voice delivering the instructions, and the high pitch T-3 sequence deployed in the first study. The third [81] examined two female voice (Mothers; Female actors) alarm messages as presented in studies 1 and 2, compared with the low and high-frequency T-3 tonal sequences. All stimuli in each study were presented at $85 \mathrm{~dB}$. 
The results across all three studies revealed that a high pitch T-3 alarm was significantly less effective in prompting awakening and a self-rescue procedure compared to the entire spectrum of experimental treatments tested. Within studies, no significant difference was observed between each variant of the maternal voice alarm messages (Name only; Instructions only; Name and Instructions) tested in the first study. Likewise, in the second study, no significant differences where observed between the male voice notification, female voice notification, and a novel hybrid (voice and low-frequency T-3) alarm. Lastly, the third study showed that a low-frequency alarm $(\mathrm{T}-3 ; 500 \mathrm{~Hz})$ significantly improved awakening and escaping time compared to a maternal voice alarm. When compared to an actor's voice alarm the low-frequency alarm $(\mathrm{T}-3 ; 500 \mathrm{~Hz})$ significantly improved awakening time, though not escaping. No significant differences were observed between awakening and escaping in the mother's or stranger's voice alarm treatments.

In summary of the research reviewed in this sub-section, symptoms of $S I$ in children appear to be heightened when awakening to a high-frequency alarm compared to a voice, or low-frequency alarms $(500 \mathrm{~Hz})$. Additionally, both the voice (Maternal Male; Actors) and low-frequency T-3 alarm types appear comparable in effectiveness against symptoms of SI. However, further research with sufficient group sizes for power to resolve the potential interaction effects between the multiple levels of the various factors is required to establish firm conclusions.

\subsubsection{Adults}

Through a novel approach incorporating naive (unprepared for the first alarm) and non-naive (prepared for the second alarm) conditions, Bruck and Horasan [85] investigated the awakening effectiveness and post-awakening objective performance of young adult participants exposed to a high frequency 'pulse' sequence $(2000-4000 \mathrm{~Hz})$ smoke alarm $(\sim 60 \mathrm{~dB})$. Subjects were allocated to one of three test groups (Stage 4, Stage 2 or REM sleep) where the alarm signal was sounded twice (naive and non-naïve, respectively) during the test session. Following awakening to the naive signal the non-naive stimulus was triggered as soon as each subject returned to their allocated sleep stage. Upon each awakening, all participants completed subjective measures (including Sleep quality and Sleep quantity) together with a computer reaction time (RT) performance task. The results from this inquiry report no significant differences for all sleep stage awakenings between the time to achieve full wakefulness in both conditions (naive; non-naive). Furthermore, no significant decrement in subject RT performance was observed following awakening compared to the control measures (before sleep and a test following a morning shower). Considering SI, the results from this study suggest that a high frequency 'pulse' alarm $(2000-4000 \mathrm{~Hz} ; \sim 60 \mathrm{~dB})$ is as successful in awakening participants and reducing symptoms of SI regardless of sleep stage at awakening compared to baseline readings. However, as there are no comparisons to a control condition or different signal designs as tested with children, the most appropriate alarm sound elements (e.g., frequency and/or volume) in context are yet to be determined.

\subsection{Music}

Hayashi et al. [57] and McFarlane et al. [83,84] have both explored the potential for music to counteract $S I$.

Hayashi et al. [57] investigated the impacts sound preference may have on SI following a 20-min daytime nap at 14:00 h. The Experimental group was awakened with a high or low-preference stimulus $(60 \mathrm{~dB})$ which persisted until the completion of the test. The Control group was awakened by an intercom. High-preference stimulus was nominated by the participants and consisted of audio described as 'popular music'. The low-preference stimuli (described as 'excitative' music by the authors) was selected by the researchers ('Mars' from 'The Planets' by Gustav Holst; 60 dB). Upon waking, participant performance was measured by completing a visual oddball task (Experimental group) or a memory search task (Control group) and reporting subjective sleepiness and comfort. The subsequent results show that the high-preference treatment produced improved RT performance compared to the 
low-preference treatment; however, there was no significant difference considering correct responses as a factor. Subjective sleepiness post-nap was significantly reduced in the high-preference condition when compared to the no-music (intercom) condition and the low-preference stimulus. No significant difference was observed between the low-preference and Control condition. Lastly, subjective comfort was superior in the high-preference condition than either the Control or low-preference stimulus. No significant difference was detected between the low-preference condition and the Control group. Taken together, these results suggest that participant preferred music may counteract symptoms of SI (RT; subjective sleepiness), and that subjective comfort may benefit when referenced against intercom type sounds or slower-paced orchestral compositions. However, beyond subjective preference, an understanding for how music may affect $S I$ is difficult to extract from this study due to the unspecified musical details of the high-preference and Control stimulus tested, and that no analysis was reported between participant performance following awakening to the intercom.

With a similar research focus to Hayashi et al. [57], McFarlane et al. (2020) reports two studies [83,84] exploring the potential impacts of sounds used for awakening in ecologically relevant, day-to-day scenarios by using remote testing to enable participants to experience treatments in their normal sleeping environment. Through the deployment of an anonymous, self-report online questionnaire, the first study [83] aimed to understand from a 'bottom-up' approach how a particular sound or music chosen for awakening may counteract $S I$, and what attributes of these sounds may contribute to the perceived reduction in SI. The study's results did not reveal any significant association between SI and the reported waking sound type and the subject's feeling towards their preferred waking sound. However, the study found that a sound which was ranked as melodic showed a significant relationship to reports of reductions in perceived SI as measured by an adapted Sleep Inertia Questionnaire (SIQ) contained in the study. Conversely, sound rated as neutral (neither unmelodic nor melodic) returned a significant relationship to increases in perceived SI. The secondary analysis of the study also revealed that a sound rated as melodic was considered to be more rhythmic than a melodically neutral interpretation. Through the analysis of the perceived effects of awakening sounds on SI, the findings from this study do indicate that the melodic content of a composition appears to be a potentially important factor for consideration in the understanding and future design of music and its ability to counteract SI.

A second study by McFarlane et al. [84] further interrogated the findings presented in the first study by testing custom-designed and composed melodic and rhythmic stimulus on SI for participants awakening in their habitual environments. All stimuli in this study shared musical characteristics (105 BPM; 4/4 m; Key of C; Timbre [woodblock; vibraphone]) to assist with result interpretation. Participants completed an online Psychomotor Vigilance Test (PVT) and questionnaire (including subjective measures KSS and Sleep quality) in two separate test sessions immediately following awakening from nocturnal sleep. Both groups responded to a Control stimulus in the first session, while in the second session, one experienced a Melodic treatment, and the second a Rhythmic treatment. The results show that the melodic treatment significantly decreased attentional lapses, false starts, and had a significantly improved PVT performance score than the control; however, there was no significant difference in RT or response speed (RS) compared to the Control. By contrast, for the Rhythmic test group, there was no significant difference observed for the PVT metrics. The results from this analysis supported and extended the initial results observed in the authors' previous study [83] and for melodies' potential to counteract symptoms of $S I$ following waking from nocturnal sleep in ecological conditions.

\section{Discussion}

In the current manuscript, the authors employed the PRISMA systematic review guidelines to identify peer reviewed research published in English on how auditory stimulus may influence participant SI upon and post-awakening. This process resulted in twelve studies being identified as meeting the criteria (Figure 1), and detailed reading of these studies provided further information 
on the types of stimuli investigated and their potential efficacy. The following summary thus serves to help highlight areas for future research to improve the current knowledge base of how different auditory treatments may influence $S I$.

\subsection{Summary of Evidence}

The results of this systematic review are derived from the analysis of twelve studies retrieved from three scientific databases (ProQuest, PubMed, Scopus) and through an author publication search (Google Scholar) and subsequent screening (Figure 1). Three primary themes encapsulate the diversity of stimulus reported in the results, including (i) Noise [58], (ii) Emergency alarms; Tone Sequences, Voice and Hybrids [77-82], and (iii) Music $[57,83,84]$ (Table 1). The context in which participants have been assessed may be further categorized into two themes, namely, emergency $[58,77-82,85,86]$, and non-emergency awakenings $[57,83,84]$. In both categories, a variety of testing methodologies have been applied within laboratory $[57,58,77-81,85]$ and field $[82-84,86]$ settings. Across studies, the participant sample size ranged from $n=14$ to $n=188$ (Table 1). The majority of articles investigating emergency awakenings have tested child participants [77-82], while in non-emergency awakenings only adults have been assessed $[57,83,84]$.

From the results reported on emergency responses in children, the evidence suggests that a low-frequency T-3 signal and voice notifications, regardless of priming or gender [78,81], are more effective in awakening and post-awakening performance than high-pitched alarms [77-79,81,82]. When comparing low-frequency and voice notifications, a low-frequency alarm has been shown to be significantly more effective than a maternal voice alarm in post-awakening performance, and significantly more effective than an actor's voice alarm arousal; however there is insufficient evidence at present to draw firm conclusions between their effectiveness with respect to SI [81]. Therefore, research to date indicates that an alarm design employing a T-3 (500 Hz square wave frequency) alarm and voice notifications are superior in counteracting the effects of $S I$ in children following abrupt awakenings than alarms with higher frequencies (e.g., $2000-4000 \mathrm{~Hz}$; Pulsed or Sequenced).

Initial results have been reported concerning auditory emergency awakenings and post-awakening performance in adults', though due to the observed absence of research that has been undertaken in this domain, the results must be interpreted with restraint. A high-frequency 'pulse' alarm (2000-4000 Hz; $\sim 60 \mathrm{~dB}$ ) has been shown to be as successful in awakening participants and reducing symptoms of $S I$ regardless of sleep stage at awakening, compared to pre-sleep baseline readings [85]. However, as there are no comparisons to a control condition or different signal designs as tested with children, the most appropriate alarm in context is yet to be resolved. Similarly, Pink noise ( $5000 \mathrm{~Hz} ; 75 \mathrm{~dB})$ has shown the potential to improve performance following awakening from an early night sleep epoch, though not in later awakenings [58]. Currently there is insufficient evidence to support firm conclusions for Pink noise and its effectiveness in children or adult awakenings as a countermeasure to SI. Between children and adult awakenings, there was reported to be no significant difference between demographics in post-awakening RT performance when responding to a high-frequency alarm [86], though due to the limited data available and low statistical power within studies, further research is required to confirm this finding.

Music does show positive results as a countermeasure for SI in non-emergency adult awakenings $[57,83,84]$. The perceived melodicity of a participant's chosen waking alarm shows a significant relationship to reductions in subjectively measured SI [83]. Preference for popular music and stimuli with melodic features have been shown to counteract SI in RT and sustained attention [57,84], and that neutral and rhythmic treatments are less effective compared to melodicity [84].

\subsection{Limitations and Recommendations}

This review provides the basis for a transparent appraisal of sound, voice, and/or music to counteract $S I$ in emergency and non-emergency awakening scenarios considering different age 
demographics. It is observed from the data extracted that there are several limitations to overcome in order to improve future research in this field. Limitations of this systematic review include the shortage of focused research specific to SI post-awakening to audio, and the heterogeneity of the assessed articles regarding study context and design, sample size, stimulus type and reporting, and SI assessment and reporting methods (objective and subjective) (Table 1).

There is an observed bias of the stimuli investigated, however, this is largely a byproduct of the research context (i.e., emergency and non-emergency) which may inform which particular alarm types (Alarm signals, Voice warnings; Music) are to be evaluated. For example, musical approaches have not been assessed within emergency settings, and conversely, alarm and voice treatments are yet to be evaluated in non-emergency settings. Future research may consider a counterbalanced design of alarm types in different contexts to assess the potential effects in contrasting settings. Furthermore, the analysis of auditory countermeasures for SI between demographics requires more research, particularly in emergency awakenings. In this context, a bias potentially exists between child awakenings and adults. Compared to what is known for auditory emergency awakenings with different stimuli in children, a knowledge gap exists in adult demographics when assessing audio treatments.

Within laboratory settings, the methodological quality of articles reviewed generally report prudent designs [58,77-81,85]; however, due to the variability of stimuli assessed, the capacity to draw conclusions across studies remains limited. Additionally, investigations conducted in laboratory settings often fail to replicate the ecological conditions in which people typically awaken [87], thus presenting challenges in the interpretation and verification of results with respect to 'real world' situations. Field studies provide superior representations of sleep-wake behavior in every-day conditions, but in doing so, there are clear technical limitations observed, specifically with respect to monitoring sleep stage at awakening [82-84,86]. For studies investigating SI in ecological settings, technological interventions (such as applying EEG sensors) often contradict study objectives, thus, compromises have been made in the data gathering process (e.g., wrist actigraphy or self-report measures) to ensure the ecological validity of such investigations. Considering this challenge, advancements in remote data-gathering technology [88] present opportunities for the refinement of such testing methods by bridging the advantages of both laboratory and field-based studies.

The refinement of the methods for assessing SI across the studies reviewed would be advantageous. In both emergency and non-emergency conditions, and in laboratory and field settings, the measuring of SI varies substantially in methodology and cognitive metrics. Test batteries which include increased testing points over time post-awakening, and the inclusion of validated objective (e.g., PVT) and subjective measures (KSS, SIQ) would further refine our knowledge for SI identification and duration.

Improvements in emergency and non-emergency contexts conducted in laboratory or field conditions would benefit by including controls in the study design to allow future comparisons between studies, stimulus, and research groups. This may include no-noise, specified standardized signals, or experimental stimuli that can be easily replicated. For studies investigating voice warnings future research would benefit through the reporting signal specifications (e.g., phrasing [rhythm, timing], and pitch ranges [Hz]), as this would assist in the comparison between targeted tone alarms, and afford technical discrimination between musical approaches. Indeed, improvements in online open access data reporting are likely to result in better data use and replication [89,90]. Similarly, general reporting of music stimuli such as genre requires greater detail as the ability to compare and validate results can present challenges. Thus, all stimuli tested (including hybrid designs) moving forward should be reported in a manner that affords uncomplicated and accurate replication by other researches in any geographic location.

Lastly, given that the primary objective for this systematic review is to report on auditory countermeasures for SI post-awakening, and that the reporting of such results are often uncategorized or secondary objectives, it is conceivable that bias in database search terms and article identification may exist. However, considering the selection criteria of this systematic review, and the contributions 
made by several article authors to this field, it is likely that the studies presented here do represent the current state of knowledge in auditory countermeasures for SI research.

\section{Conclusions}

This systematic review provides an up to date summary of existing original empirical research published in English on auditory countermeasures for SI post-awakening. From research spanning 1992 to 2020, the findings illustrate that there are two lines of inquiry which interrogate SI including emergency, and non-emergency test scenarios. The results indicate that for children awakening in emergency conditions, a low pitch alarm or voice notifications appear to be more effective in counteracting the effects of $S I$, than alarms with higher frequencies, particularly in memory and reaction time. However, further research is required to confirm an effective difference between low-frequency and voice alarms. Similarly, for adults abruptly awakened, there is currently insufficient evidence to support firm conclusions regarding alarm types and voice signals concerning SI post-awakening. Positive results have been found in non-emergency awakenings with respect to musical treatments in adults, particularly preferred popular music, and alarms with melodic qualities. In both categories investigating $S I$, the results observed reflect the potential for sound and music to counteract $S I$. Furthermore, there are identified opportunities to capitalize upon, that in turn will strengthen the knowledge base in this field. These include increasing research efforts in adult emergency awakenings with different stimulus treatments, comparing treatments between demographics, and further exploring musical treatments in children/adult and emergency conditions. Additionally, refining testing methods in field studies will assist in knowledge production for how sound may counteract $S I$ in ecological conditions, and help design experiments that might seek to better understand the neurophysiology of how sound is processed by the brain [91] and a mechanistic account of how to reduce SI. Acknowledging the potentially detrimental effects resulting from $S I$, the results from this systematic review may be an important reference for researchers and professionals in the fields of auditory perception, sleep and cognitive psychology, and sound design. Industry would also benefit from this systematic review, particularly in first response, transport, and high-risk occupations.

Supplementary Materials: Supplementary materials can be found at http://www.mdpi.com/2624-5175/2/4/31/s1. Table S1: PRISMA 2009 Checklist.

Author Contributions: Conceptualization, S.J.M., A.G.D.; Data gathering; S.J.M.; methodology, S.J.M.; validation, S.J.M., A.G.D.; formal analysis, S.J.M.; investigation, S.J.M.; resources, S.J.M.; data curation, S.J.M.; writing-original draft preparation, S.J.M.; writing-review and editing, S.J.M., J.E.G., D.S.V., A.G.D.; visualization, S.J.M.; supervision, J.E.G., D.S.V., A.G.D.; project administration, S.J.M.; funding acquisition, S.J.M. All authors have read and agreed to the published version of the manuscript.

Funding: S.J.M. acknowledges the Australian Government's support of his research through the "Australian Government Research Training Program Scholarship" (00122A).

Conflicts of Interest: The authors declare no conflict of interest. The funder had no role in the design of the study; in the collection, analyses, or interpretation of data; in the writing of the manuscript, or in the decision to publish the results.

\section{References}

1. Paterson, J.L.; Aisbett, B.; Ferguson, S.A. Sound the alarm: Health and safety risks associated with alarm response for salaried and retained metropolitan firefighters. Saf. Sci. 2016, 82, 174-181. [CrossRef]

2. Tassi, P.; Muzet, A. Sleep inertia. Sleep Med. Rev. 2000, 4, 341-353. [CrossRef] [PubMed]

3. Trotti, L.M. Waking up is the hardest thing I do all day: Sleep inertia and sleep drunkenness. Sleep Med. Rev. 2017, 35, 76-84. [CrossRef] [PubMed]

4. Hilditch, C.J.; McHill, A.W. Sleep inertia: Current insights. Nat. Sci. Sleep 2019, 11, 155-165. [CrossRef] [PubMed]

5. Wertz, A.T.; Ronda, J.M.; A Czeisler, C.; Wright, J.K.P. Effects of Sleep Inertia on Cognition. JAMA 2006, 295, 159. [CrossRef] 
6. Wilkinson, R.T.; Stretton, M. Performance after awakening at different times of night. Psychon. Sci. 1971, 23, 283-285. [CrossRef]

7. Sallinen, M.; Harma, M.; Akerstedt, T.; Rosa, R.; Lillqvist, O. Promoting alertness with a short nap during a night shift. J. Sleep Res. 1998, 7, 240-247. [CrossRef]

8. Jewett, M.E.; Wyatt, J.K.; Cecco, A.R.; Khalsa, S.B.; Dijk, D.; Czeisler, C.A. Time course of sleep inertia dissipation in human performance and alertness. J. Sleep Res. 1999, 8, 1-8. [CrossRef]

9. Dinges, D.F. Are you awake? Cognitive performance and reverie during the hypnopompic state. In Sleep and Cognition; Kihlstrom, J.F., Schacter, D.L., Eds.; American Psychological Association (APA): Washington, DC, USA, 2004; pp. 159-175.

10. Broughton, R.J. Sleep disorders: Disorders of arousal?: Enuresis, somnambulism, and nightmares occur in confusional states of arousal, not in "dreaming sleep". Science 1968, 159, 1070-1078. [CrossRef]

11. Bruck, D.; Pisani, D.L. The effects of sleep inertia on decision-making performance. J. Sleep Res. 1999, 8, 95-103. [CrossRef]

12. Bonnet, M.H. Memory for Events Occurring During Arousal From Sleep. Psychophysiology 1983, $20,81-87$. [CrossRef] [PubMed]

13. Webb, W.B.; Agnew, H. Reaction time and serial response efficiency on arousal from sleep. Percept. Mot. Ski. 1964, 18, 783-784. [CrossRef] [PubMed]

14. Dinges, D.F.; Orne, M.T.; Orne, E.C. Assessing performance upon abrupt awakening from naps during quasi-continuous operations. Behav. Res. Methods Instrum. Comput. 1985, 17, 37-45. [CrossRef]

15. Balkin, T.J.; Badia, P. Relationship between sleep inertia and sleepiness: Cumulative effects of four nights of sleep disruption/restriction on performance following abrupt nocturnal awakening. Biol. Psychol. 1988, 27, 245-258. [CrossRef]

16. Bonnet, M.H. Performance and Sleepiness as a Function of Frequency and Placement of Sleep Disruption. Psychophysiology 1986, 23, 263-271. [CrossRef] [PubMed]

17. Ferrara, M.; De Gennaro, L.; Bertini, M. The effects of slow-wave sleep (SWS) deprivation and time of night on behavioral performance upon awakening. Physiol. Behav. 2000, 68, 55-61. [CrossRef]

18. Ferrara, M.; De Gennaro, L.; Bertini, M. Time-course of sleep inertia upon awakening from nighttime sleep with different sleep homeostasis conditions. Aviat. Space Environ. Med. 2000, 71, 225-229. [PubMed]

19. Ferrara, M.; De Gennaro, L.; Casagrande, M.; Bertini, M. Selective slow-wave sleep deprivation and time-of-night effects on cognitive performance upon awakening. Psychophysiology 2000, 37, 440-446. [CrossRef]

20. Ferrara, M.; De Gennaro, L. The sleep inertia phenomenon during the sleep-wake transition: Theoretical and operational issues. Aviat. Space Environ. Med. 2000, 71, 843-848.

21. Scheer, F.A.J.L.; Shea, T.J.; Hilton, M.F.; Shea, S.A. An Endogenous Circadian Rhythm in Sleep Inertia Results in Greatest Cognitive Impairment upon Awakening during the Biological Night. J. Biol. Rhythm. 2008, 23, 353-361. [CrossRef]

22. Silva, E.J.; Duffy, J.F. Sleep inertia varies with circadian phase and sleep stage in older adults. Behav. Neurosci. 2008, 122, 928-935. [CrossRef] [PubMed]

23. Van Dongen, H.P.A.; Price, N.J.; Mullington, J.M.; Szuba, M.P.; Kapoor, S.C.; Dinges, D.F. Caffeine eliminates psychomotor vigilance deficits from sleep inertia. Sleep 2001, 24, 813-819. [CrossRef] [PubMed]

24. Signal, T.L.; Berg, M.J.V.D.; Mulrine, H.M.; Gander, P.H. Duration of sleep inertia after napping during simulated night work and in extended operations. Chronobiol. Int. 2012, 29, 769-779. [CrossRef] [PubMed]

25. Santhi, N.; Groeger, J.A.; Archer, S.N.; Gimenez, M.; Schlangen, L.J.M.; Dijk, D.-J. Morning Sleep Inertia in Alertness and Performance: Effect of Cognitive Domain and White Light Conditions. PLoS ONE 2013, 8, e79688. [CrossRef] [PubMed]

26. Achermann, P.; Werth, E.; Dijk, D.J.; A Borbely, A. Time course of sleep inertia after nighttime and daytime sleep episodes. Arch. Ital. Biol. 1995, 134, 109-119.

27. Horne, J.; Moseley, R. Sudden early morning awakening impairs immediate tactical planning in a changing 'emergency' scenario. J. Sleep Res. 2010, 20, 275-278. [CrossRef]

28. Government of India Ministry of Civil Aviation. Report on Accident to Air India Express Boeing 737-800 Aircraft VT-AXV on 22nd May 2010 at Mangalore; Government of India Ministry of Civil Aviation: New Delhi, India, 2010. 
29. Armentrout, J.J.; A Holland, D.; O'Toole, K.J.; Ercoline, W.R. Fatigue and related human factors in the near crash of a large military aircraft. Aviat. Space Environ. Med. 2006, 77, 963-970.

30. Wu, B.; Wang, Y.; Wu, X.; Liu, D.; Xu, D.; Wang, F. On-orbit sleep problems of astronauts and countermeasures. Mil. Med Res. 2018, 5, 17. [CrossRef]

31. Flynn-Evans, E.; Gregory, K.; Arsintescu, L.; Whitmire, A. Evidence Report: Risk of Performance Decrements and Adverse Health Outcomes Resulting from Sleep Loss, Circadian Desynchronization, and Work Overload; National Aeronautics and Space Administration: Houston, TX, USA, 2016.

32. Caldwell, J.A.; Frazinko, B.F.; Caldwell, B.S.; Caldwell, J.L. Fatigue in Aviation Sustained Operations, the Utility of Napping, and the Problem of Sleep Inertia; Army Aeromedical Research Lab: Fort Rucker, AL, USA, 2002.

33. Rosekind, M.R.; Smith, R.M.; Miller, D.L.; Co, E.L.; Gregory, K.B.; Webbon, L.L.; Gander, P.H.; Lebacqz, J.V. Alertness management: Strategic naps in operational settings. J. Sleep Res. 1995, 4, 62-66. [CrossRef]

34. Caldwell, J.A. The impact of fatigue in air medical and other types of operations: A review of fatigue facts and potential countermeasures. Air Med. J. 2001, 20, 25-32. [CrossRef]

35. Caldwell, J.A.; Mallis, M.M.; Paul, M.A.; Miller, J.C.; Neri, D.F. Fatigue Countermeasures in Aviation. Aviat. Space Environ. Med. 2009, 80, 29-59. [CrossRef] [PubMed]

36. Hartzler, B.M. Fatigue on the flight deck: The consequences of sleep loss and the benefits of napping. Accid. Anal. Prev. 2014, 62, 309-318. [CrossRef] [PubMed]

37. Signal, T.L.; Gander, P.H.; Anderson, H.; Brash, S. Scheduled napping as a countermeasure to sleepiness in air traffic controllers. J. Sleep Res. 2009, 18, 11-19. [CrossRef] [PubMed]

38. Takahashi, M.; Nakata, A.; Haratani, T.; Ogawa, Y.; Arito, H. Post-lunch nap as a worksite intervention to promote alertness on the job. Ergonomics 2004, 47, 1003-1013. [CrossRef]

39. Brooks, A.; Lack, L. A Brief Afternoon Nap Following Nocturnal Sleep Restriction: Which Nap Duration is Most Recuperative? Sleep 2006, 29, 831-840. [CrossRef]

40. Hilditch, C.J.; Dorrian, J.; Centofanti, S.A.; Van Dongen, H.P.; Banks, S. Sleep inertia associated with a 10-min nap before the commute home following a night shift: A laboratory simulation study. Accid. Anal. Prev. 2017, 99, 411-415. [CrossRef]

41. Tassi, P.; Bonnefond, A.; Engasser, O.; Hoeft, A.; Eschenlauer, R.; Muzet, A. EEG spectral power and cognitive performance during sleep inertia: The effect of normal sleep duration and partial sleep deprivation. Physiol. Behav. 2006, 87, 177-184. [CrossRef]

42. Miccoli, L.; Versace, F.; Koterle, S.; Cavallero, C. Comparing Sleep-Loss Sleepiness and Sleep Inertia: Lapses Make the Difference. Chronobiol. Int. 2008, 25, 725-744. [CrossRef]

43. Sasaki, N.; Ozono, R.; Teramen, K.; Yamashita, H.; Fujiwara, S.; Kihara, Y. P6215. Poor sleep and cardiovascular disease: Different pattern of sleep disturbance in ischemic heart disease and stroke. Eur. Hear. J. 2017, $38,1$. [CrossRef]

44. Hafner, M.; Stepanek, M.; Taylor, J.; Troxel, W.; Stolk, C. Why sleep matters: The economic costs of insufficient sleep. Rand Health Q. 2017, 6, 11. [CrossRef]

45. A Centofanti, S.; Dorrian, J.; Grant, C.; Stepień, J.; Coates, A.; Lushington, K.; Evans, A.; Lange, S.R.; Banks, S. 0200 The Effectiveness Of Caffeine Gum In Reducing Sleep Inertia Following A 30min Nighttime Nap Opportunity: Preliminary Results. Sleep 2018, 41, A78. [CrossRef]

46. Reyner, L.A.; Horne, J.A. Suppression of sleepiness in drivers: Combination of caffeine with a short nap. Psychophysiology 1997, 34, 721-725. [CrossRef] [PubMed]

47. Hayashi, M.; Masuda, A.; Hori, T. The alerting effects of caffeine, bright light and face washing after a short daytime nap. Clin. Neurophysiol. 2003, 114, 2268-2278. [CrossRef]

48. Newman, R.A.; Kamimori, G.H.; Wesensten, N.J.; Picchioni, D.; Balkin, T.J. Caffeine Gum Minimizes Sleep Inertia. Percept. Mot. Ski. 2013, 116, 280-293. [CrossRef]

49. Figueiro, M.G.; Sahin, L.; Roohan, C.; Kalsher, M.; Plitnick, B.; Rea, M.S. Effects of red light on sleep inertia. Nat. Sci. Sleep 2019, 11, 45-57. [CrossRef]

50. Geerdink, M.; Walbeek, T.J.; Beersma, D.G.; Hommes, V.; Gordijn, M.C.M. Short Blue Light Pulses (30 Min) in the Morning Support a Sleep-Advancing Protocol in a Home Setting. J. Biol. Rhythm. 2016, 31, 483-497. [CrossRef]

51. Gabel, V.; Maire, M.; Reichert, C.F.; Chellappa, S.L.; Schmidt, C.; Hommes, V.; Viola, A.U.; Ecajochen, C. Effects of Artificial Dawn and Morning Blue Light on Daytime Cognitive Performance, Well-being, Cortisol and Melatonin Levels. Chronobiol. Int. 2013, 30, 988-997. [CrossRef] 
52. Kräuchi, K.; Cajochen, C.; Wirz-Justice, A. Waking up properly: Is there a role of thermoregulation in sleep inertia? J. Sleep Res. 2004, 13, 121-127. [CrossRef]

53. Kräuchi, K.; Knoblauch, V.; Wirz-Justice, A.; Cajochen, C. Challenging the sleep homeostat does not influence the thermoregulatory system in men: Evidence from a nap vs. sleep-deprivation study. Am. J. Physiol. Integr. Comp. Physiol. 2006, 290, R1052-R1061. [CrossRef]

54. A Kaplan, K.; Talavera, D.C.; Harvey, A.G.; Kaplan, K.A. Rise and shine: A treatment experiment testing a morning routine to decrease subjective sleep inertia in insomnia and bipolar disorder. Behav. Res. Ther. 2018, 111, 106-112. [CrossRef]

55. Jay, S.M.; Carley, D.M.; Aisbett, B.; Ferguson, S.A.; Paterson, J.L. Can stress act as a sleep inertia countermeasure when on-call? Biol. Rhythm. Res. 2018, 50, 429-439. [CrossRef]

56. Hilditch, C.J.; Dorrian, J.; Banks, S. Time to wake up: Reactive countermeasures to sleep inertia. Ind. Health 2016, 54, 528-541. [CrossRef] [PubMed]

57. Hayashi, M.; Uchida, C.; Shoji, T.; Hori, T. The effects of the preference for music on sleep inertia after a short daytime nap. Sleep Biol. Rhythm. 2004, 2, 184-191. [CrossRef]

58. Tassi, P.; Nicolas, A.; Dewasmes, G.; Eschenlauer, R.; Ehrhart, J.; Salame, P.; Muzet, A.; Libert, J.P. Effects of Noise on Sleep Inertia as a Function of Circadian Placement of a One-Hour Nap. Percept. Mot. Ski. 1992, 75, 291-302. [CrossRef]

59. Poulton, E.C. Arousing environmental stresses can improve performance, whatever people say. Aviat. Space Environ. Med. 1976, 47, 1193-1204.

60. Harrison, D.W.; Kelly, P.L. Age Differences in Cardiovascular and Cognitive Performance under Noise Conditions. Percept. Mot. Ski. 1989, 69, 547-554. [CrossRef] [PubMed]

61. Hockey, G.R.J. Effect of loud noise on attentional selectivity. Q. J. Exp. Psychol. 1970, 22, 28-36. [CrossRef]

62. Asutay, E.; Västfjäll, D. Exposure to arousal-inducing sounds facilitates visual search. Sci. Rep. 2017, 7, 10363. [CrossRef]

63. Davies, D.R.; Lang, L.; Shackleton, V.J. The effects of music and task difficulty on performance at a visual vigilance task. Br. J. Psychol. 1973, 64, 383-389. [CrossRef]

64. Corhan, C.M.; Gounard, B.R. Types of Music, Schedules of Background Stimulation, and Visual Vigilance Performance. Percept. Mot. Ski. 1976, 42, 662. [CrossRef]

65. Mayfield, C.; Moss, S.; Mayheld, C. Effect of Music Tempo on Task Performance. Psychol. Rep. 1989, 65, 1283-1290. [CrossRef] [PubMed]

66. Riby, L.M. The joys of spring: Changes in mental alertness and brain function. Exp. Psychol. 2013, 60, 71-79. [CrossRef] [PubMed]

67. Husain, G.; Thompson, W.F.; Schellenberg, E.G. Effects of musical tempo and mode on arousal, mood, and spatial abilities. Music Percept. Interdiscip. J. 2002, 20, 151-171. [CrossRef]

68. Thomas, I.; Bruck, D. Awakening of sleeping people: A decade of research. Fire Technol. 2008, 46, 743-761. [CrossRef]

69. Moher, D.; Liberati, A.; Tetzlaff, J.; Altman, D.G. Preferred reporting items for systematic reviews and meta-analyses: The PRISMA Statement. PLoS Med. 2009, 6, e1000097. [CrossRef] [PubMed]

70. Moher, D.; PRISMA-P Group; Shamseer, L.; Clarke, M.; Ghersi, D.; Liberati, A.; Petticrew, M.; Shekelle, P.; Stewart, L.A. Preferred reporting items for systematic review and meta-analysis protocols (PRISMA-P) 2015 statement. Syst. Rev. 2015, 4, 1. [CrossRef] [PubMed]

71. Drucker, A.M.; Fleming, P.; Chan, A.-W. Research Techniques Made Simple: Assessing Risk of Bias in Systematic Reviews. J. Investig. Dermatol. 2016, 136, e109-e114. [CrossRef]

72. Gusenbauer, M. Google Scholar to overshadow them all? Comparing the sizes of 12 academic search engines and bibliographic databases. Scientometrics 2018, 118, 177-214. [CrossRef]

73. Li, T.; Higgins, J.P.; Deeks, J.J. Collecting data. In Cochrane Handbook for Systematic Reviews of Interventions, 2nd ed.; John Wiley \& Sons: Chichester, UK, 2019; pp. 109-141. [CrossRef]

74. Higgins, J.P.; Green, S. Cochrane Handbook for Systematic Reviews of Interventions; John Wiley \& Sons: Hoboken, NJ, USA, 2019.

75. Kmet, L.M.; Cook, L.S.; Lee, R.C. Standard Quality Assessment Criteria for Evaluating Primary Research Papers from a Variety of Fields. In Edmonton: Alberta Heritage Foundation for Medical Research (AHFMR); AHFMR—HTA Initiative \#13: Edmonton, AB, Canada, 2004. 
76. Popay, J.; Roberts, H.; Sowden, A.; Petticrew, M.; Arai, L.; Rodgers, M.; Britten, N. Guidance on the Conduct of Narrative Synthesis in Systematic Reviews: A Product from the ESRC Methods Programme, 1st ed.; Lancaster University: Lancaster, UK, 2006; Volume 10, pp. 1018-4643.

77. Smith, G.A.; Splaingard, M.; Hayes, J.R.; Xiang, H. Comparison of a personalized parent voice smoke alarm with a conventional residential tone smoke alarm for awakening children. Pediatrics 2006, 118, 1623-1632. [CrossRef]

78. Smith, G.A.; Chounthirath, T.; Splaingard, M. Effectiveness of a voice smoke alarm using the child's name for sleeping children: A randomized trial. J. Pediatrics 2019, 205, 250-256. [CrossRef]

79. Smith, G.A.; Chounthirath, T.; Splaingard, M. Comparison of the effectiveness of female voice, male voice, and hybrid voice-tone smoke alarms for sleeping children. Pediatr. Res. 2020. [CrossRef] [PubMed]

80. Splaingard, M.; Hayes, J.; Smith, G.A. Impairment of reaction time among children awakened during stage 4 sleep. Sleep 2007, 30, 104-108. [CrossRef] [PubMed]

81. Smith, G.A.; Chounthirath, T.; Splaingard, M. Do sleeping children respond better to a smoke alarm that uses their mother's voice? Acad. Pediatrics 2020, 20, 319-326. [CrossRef] [PubMed]

82. Bruck, D.; Reid, S.; Kouzma, J.; Ball, M. The effectiveness of different alarms in waking sleeping children. In Human Behavior in Fire: Public Fire Safety-Professionals in Partnership, Proceedings of the 3rd International Symposium, Belfast, Northern Ireland, 1-3 September 2004; Interscience Communications Ltd.: London, UK, 2004; pp. 279-289.

83. McFarlane, S.J.; Garcia, J.; Verhagen, D.S.; Dyer, A.G. Alarm tones, music and their elements: Analysis of reported waking sounds to counteract sleep inertia. PLoS ONE 2020, 15, e215788. [CrossRef]

84. McFarlane, S.J.; Garcia, J.E.; Verhagen, D.; Dyer, A.G. Auditory Countermeasures for Sleep Inertia: Exploring the Effect of Melody and Rhythm in an Ecological Context. Clocks Sleep 2020, 2, 208-224. [CrossRef]

85. Bruck, D.; Horasan, M. Non-arousal and non-action of normal sleepers in response to a smoke detector alarm. Fire Saf. J. 1995, 25, 125-139. [CrossRef]

86. Bruck, D. Non-awakening in children in response to a smoke detector alarm. Fire Saf. J. 1999, 32, 369-376. [CrossRef]

87. Ancoli-Israel, S.; Cole, R.; Alessi, C.; Chambers, M.; Moorcroft, W.; Pollak, C.P. The Role of Actigraphy in the Study of Sleep and Circadian Rhythms. Sleep 2003, 26, 342-392. [CrossRef]

88. McDowell, K.; Lin, C.-T.; Oie, K.S.; Jung, T.-P.; Gordon, S.; Whitaker, K.W.; Li, S.-Y.; Lu, S.-W.; Hairston, W.D. Real-World Neuroimaging Technologies. IEEE Access 2013, 1, 131-149. [CrossRef]

89. Huston, P.; Edge, V.L.; Bernier, E. Reaping the benefits of Open Data in public health. Can. Commun. Dis. Rep. 2019, 45, 252-256. [CrossRef]

90. Willinsky, J. The Access Principle: The Case for Open Access to Research and Scholarship; MIT Press: Cambridge, MA, USA, 2006.

91. Albouy, P.; Benjamin, L.; Morillon, B.; Zatorre, R.J. Distinct sensitivity to spectrotemporal modulation supports brain asymmetry for speech and melody. Science 2020, 367, 1043-1047. [CrossRef] [PubMed]

Publisher's Note: MDPI stays neutral with regard to jurisdictional claims in published maps and institutional affiliations.

(C) 2020 by the authors. Licensee MDPI, Basel, Switzerland. This article is an open access article distributed under the terms and conditions of the Creative Commons Attribution (CC BY) license (http://creativecommons.org/licenses/by/4.0/). 